\title{
MODELLING AND EXPERIMENTAL TESTING OF HYBRID JOINTS MADE OF: ALUMINIUM ADHERENDS, ADHESIVE LAYERS AND RIVETS FOR AEROSPACE APPLICATIONS
}

\footnotetext{
The contemporary demands in different branches of engineering require application of new multi-component materials and structural systems. Appropriately chosen joining technology can offer significant enhancement of structural system performance in terms of effectiveness, reliability, safety and other design criteria. The modern applications of complex joints are of great technological interest as they permit to combine and to enhance the individual effects of each kind of joint. This is of great importance for modern applications in different branches of engineering: aerospace, mechanical and civil.

Therefore in this paper we will focus on the analysis of mechanical response of adhesive joint of aluminium strips reinforced by rivets.

The aim of the paper is to investigate experimentally the mechanical behaviour of adhesive joint of aluminium strips reinforced by rivets for industrial applications in aerospace. The considered joint was subjected to uniaxial loading. The tests in this paper were performed for:

- classical adhesive joint in order to investigate material parameters for numerical modelling of the hybrid joint

- hybrid joining of the structural elements in order to investigate the reinforcement effect.

The experiments with application of digital image ARAMIS system allowed for on-line monitoring of the deformation process of the considered joining elements. The particular distributions of displacement fields at the joint surface were estimated for any stage of loading process.

Numerical modelling was performed for experimentally investigated specimens. The materials parameters, necessary for calculation, were estimated from experiments. FEA modelling was done with the help of ABAQUS code.

Keywords: hybrid joints, numerical modelling, experiments
}

\section{Introduction}

Current technological demands in modern branches of engineering require application of novel composites or structural elements made of different materials and joined by different, more efficient techniques. The advanced composites are manufactured as various mixtures of many components, e.g. [1-3]. The internal structure of newly created composites could be designed for particular needs of the end users, e.g. military, aerospace, civil etc. One of the most important proposition are functionally graded materials, having specifically oriented gradation of mechanical properties, e.g. [1,4-7]. Other types of internal structure are materials made of:

(1) a sequence of different layers with various mechanical features, e.g. [8],

(2) grains surrounded by other material, i.e. thin interface layers, [9-13],

(3) thermal barrier coatings in the form of sequence of ceramic layers covering turbine blades (e.g.[14-16]),

(4) 2 structural materials joined by adhesive e.g. [17-22].
In this paper we will focus on the new approach to joining of structural parts of aeroplanes. Classically, connection technology of structural elements can be done by using single joining technique as: riveting, spot welding, clinching or adhesive bonding (e.g. [22,23]). However, improvement of the mechanical response of the joints can be performed by combination of two simple joining techniques, e.g.: riveted-bonding (e.g. [24]), spot welded-bonding (e.g. [25-28], clinched-bonding (e.g. [29-31]), etc.

Therefore, the aim of this work will be analysis of double lap joint of steel adherends by adhesive bonding and mechanical fasteners - riveting, subjected to uni-axial loading. The numerical modeling is complex process, as solution of the problem requires application of damage and fracture criteria (e.g. [32-36]) for both mechanical fasteners and adhesive. The new model is formulated in ABAQUS in order to include description of complex damage processes leading to the final failure of the joint. The paper is completed by experimental test confirming correctness of the proposed numerical calculations.

\footnotetext{
* LUBLIN UNIVERSITY OF TECHNOLOGY, 20-618 LUBLIN, 40 NADBYSTRZYCKA STR., POLAND

\# Corresponding author: t.sadowski@pollub.p
} 


\section{The samples geometry, materials used and experimental tests}

The investigated double lap joint has dimensions presented in Fig. 1. The sample consists of 3 steel strips and adhesive layer and one aluminum rivet. To estimate the level of reinforcement of the adhesive joint by the mechanical fastener we additionally consider purely adhesive joint.

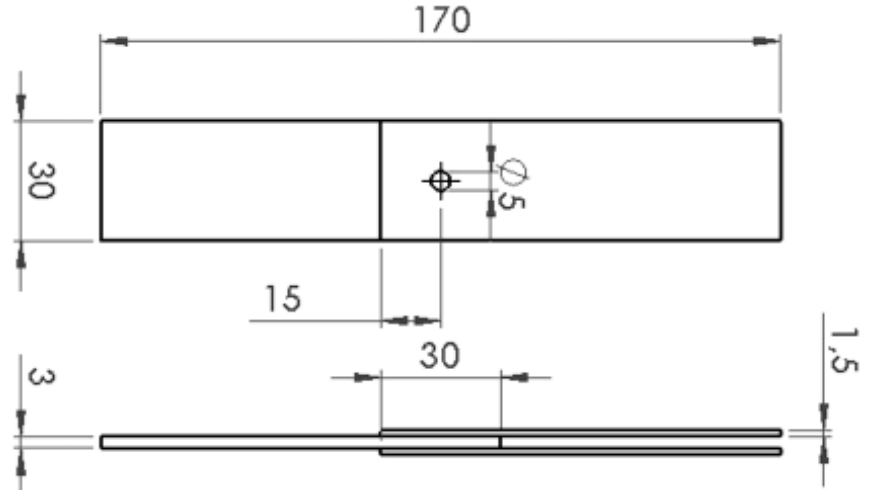

Fig. 1. Geometry of the double lap joint

The steel used for the middle part of the sample $(3 \mathrm{~mm}$ thickness) was much stronger in comparison to that used for the 2 external thinner sheets ( $1.5 \mathrm{~mm}$ thickness). The mechanical properties of the steel sheets were the following:

(1) the Young's modulus was equal to $E_{s}=210 \mathrm{GPa}$,

(2) the Poisson's ratio was equal to $v=0.3$,

(3) the yield strength $-\sigma_{y}=300 \mathrm{MPa}$,

(4) the maximum stress $-\sigma^{\max }=385 \mathrm{MPa},-$ for corresponding strain equal to $\varepsilon=0.2$.

The rivets are made of aluminium alloy having the Young's modulus equal to $E_{r}=70 \mathrm{GPa}$, whereas Poisson's ratio is $v=0.3$. The strength of the rivets is $-\sigma_{u}=130 \mathrm{MPa}$, The mandrel was made of steel. The exerted force by the mandrel for the single rivet was equal to $F_{r}=2 \mathrm{kN}$.

The adhesive used for the double lap joint was the heat curing epoxy adhesive Hysol 9514 (Loctite, Ireland). In order to get maximum tensile and shear strengths, the specimens were kept in the curing temperature $150^{\circ} \mathrm{C}$ for 30 min, according to producer's recommendation. The shear strength estimated by experimental testing was equal to $\tau_{\mathrm{adh}}^{\max }=45 \mathrm{MPa}$, whereas tensile strength $\sigma_{\text {adh }}^{\max }=44 \mathrm{MPa}$.

The servohydraulic machine MTS $100 \mathrm{kN}$ was used for experimental testing. The specimens were subjected to tensile deformation process (Fig. 2) with a crosshead displacement rate of $2 \mathrm{~mm} / \mathrm{min}$. The Digital Image Correlation (DIC) system ARAMIS was used for monitoring deformation process up to the final failure. At this stage we observed full decohesion of the adhesive layers and shear failure of the rivet, Fig. 3. One can observe three adherends of the failed adhesive-riveted joint after final failure. It can be noticed that the body of the rivet is considerably deformed due to a shearing process, whereas the steel plates are deformed at the hole edge. The maximum deformation in the rivet takes place in its central part, which corresponds to the middle strip region.

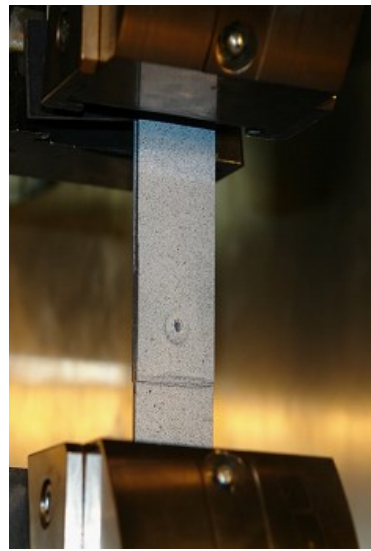

Fig. 2. The experimental stand with sample prepared for test

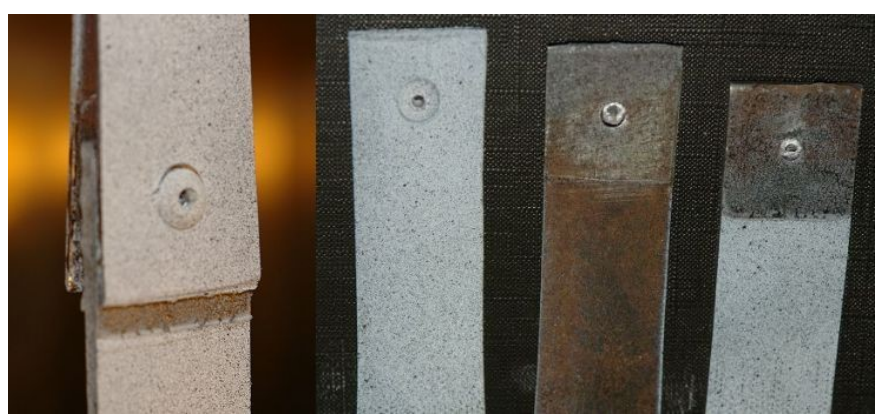

Fig. 3. Final failure of the adhesive-rivet joint

Figure 4 collects all experimental results, i.e. load-displacement curves, concerning purely adhesive and rivet-adhesive joints. The shapes of these diagrams are characteristic, i.e.

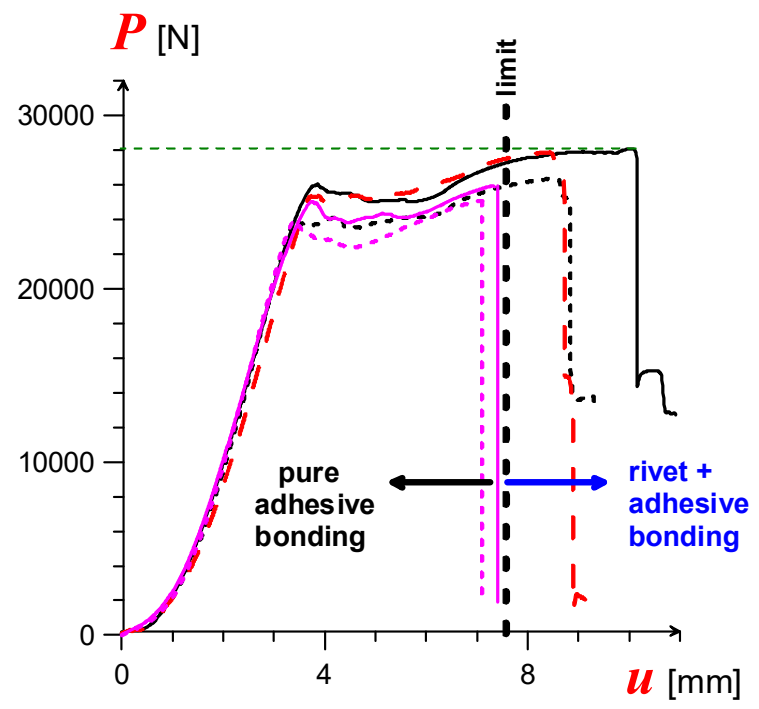

Fig. 4. Results of experimental tests obeying (a) pure adhesive joints, (b) adhesive - rivet joints

After the first linear part, the curves reached the local maximum at which the adhesive layers start to fail. Then, the 
bonding area load starts to reduce. Therefore, one can observe a local small decrease of the force and then stabilisation corresponding to further gradual development of failure zones in adhesive layers, followed by almost linear increase up to the maximum load.

The complex rivet-adhesive joints have the same geometry, Fig. 1. The adhesive was applied on the cleaned steel adherends and then the joint was reinforced by a simple rivet. The whole joint was cured at $150^{\circ} \mathrm{C}$ for $30 \mathrm{~min}$. The averaged thickness of the adhesive was equal to $0.1 \mathrm{~mm}$. The load-displacement curves of the rivet-adhesive joints are similar to those of the adhesive joints. However, one can observe an increase of the failure load due to the presence of the rivet and synergy between the adhesive and the rivet. Moreover, deformability of the joints is much higher, i.e. we observed significant increase of the displacement at failure. The fracture of the joints took place by debonding of 2 adhesive interfaces and cutting of the rivet. The fracture surface of exemplary sample is presented in Fig. 3.

Effectiveness of the complex joint can be estimated by energy absorption (EA) of the sample at fracture. The EA in case of adhesive joint is equal to $122 \mathrm{~J}$, whereas in case of the complex joint EA $=165 \mathrm{~J}$. In conclusion the increase of the energy absorption capacity is at the level $35 \%$ and the synergy between the adhesive and the rivet is very substantial.

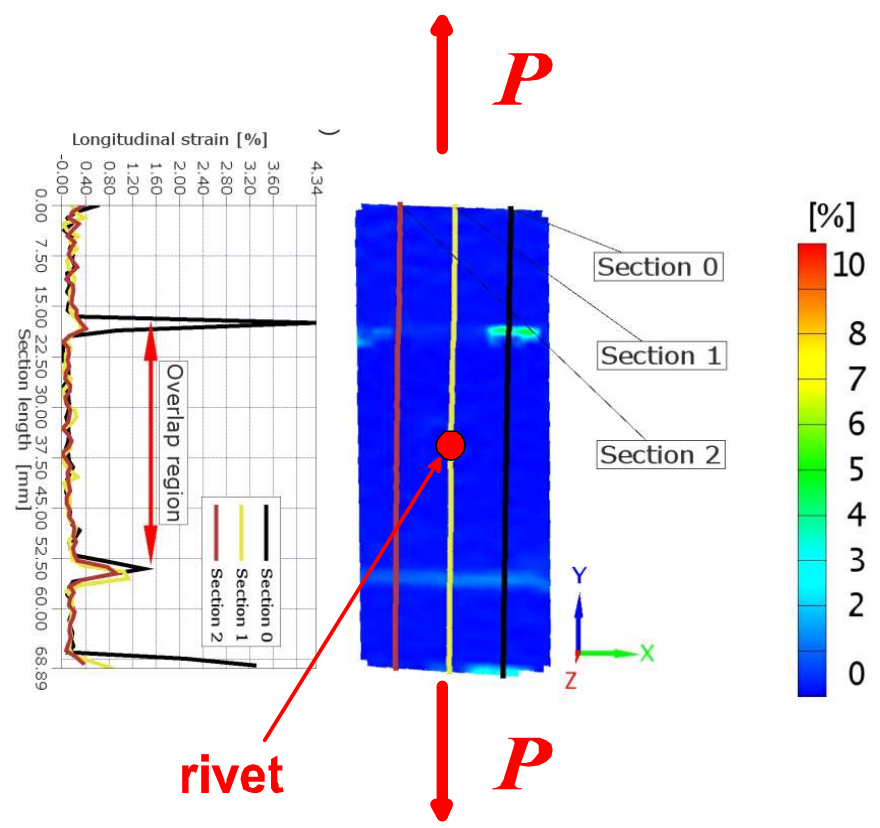

Fig. 5. Vertical strain distribution estimated by DIC system ARAMIS

Distribution of the strain state measured by the ARAMIS in the rivet-adhesive joint is presented in Fig. 5. One can notice the strain concentrations at the beginning and end of the overlap regions, which is due to the sudden change of the cross section thickness. In the advanced state of deformation one can observe development of plastic strains in the external steel plates and in the final stage of loading, when the decohesion at adhesive interfaces reached the cross section containing the rivet and the final failure took place, Fig. 3.

\section{The Finite Element Model (FEM) of the rivet-adhesive joint}

The numerical Finite Element (FE) analysis was done with application of the commercial code ABAQUS. For creation of the FE numerical models we applied:

(1) standard the FE type C3D8R with damage to model steel adherends and the rivet,

(2) cohesive elements COH3D8R for creation of the adhesive layer.

The analysis includes both: material and geometrical nonlinearities.

The properties of the used materials were the following:

(1) the steel adherends: $E_{\mathrm{st}}=205 \mathrm{GPa}, v_{\mathrm{st}}=0.3, \sigma_{y}^{\mathrm{st}}=300 \mathrm{MPa}$,

(2) the adhesive layer: $E_{\mathrm{ad}}=205 \mathrm{GPa}, v_{\mathrm{ad}}=0.3$,

(3) the aluminium rivet: $E_{\text {riv }}=205 \mathrm{GPa}, v_{\text {riv }}=0.33, \sigma_{y}^{\text {riv }}=300$ MPa.

To simulate gradual decohesion and the failure process of the adhesive layer, a cohesive zone model was applied in FE analysis. For our model we used so called triangular stressseparation law (correlation $\sigma(\lambda)$ ) for 1-D tension, introducing a non-dimensional opening displacement equal to $\lambda=u_{n} / \delta^{\max }$. $u_{n}$ is the normal opening displacement and $\delta^{\max }$ is a maximum opening displacement, corresponding to failure of the material. $\sigma_{\mathrm{adh}}^{\max }$ is the maximum stress threshold for the adhesive, which corresponds to damage initiation. The fracture energy $G_{I c}$ of the adhesive is introduced to the model as an area under the curve $\sigma(\lambda)$. In the general 3-D cases a complex mode of damage growth occurs. Then one can introduce a normal opening displacement $u_{n}$ for the tension mode and a tangential displacement $u_{\tau}$ for the shear mode. In the 3-D case we define non-dimensional displacements $\lambda_{n}$ and $\lambda_{\tau}$ :

- for normal damage mode $\lambda_{n}=u_{n} / \delta^{\max }$,

- $\quad$ for shear damage mode $\lambda_{\tau}=u_{\tau} / \delta_{\tau}^{\max }$,

where $\delta_{n}^{\max }, \delta_{\tau}^{\max }$ are the maximum opening and shear displacements, corresponding to failure of the material in the opening and shear modes. We assume for the considered 3-D case that the damage initiation criterion will depend on current state of stress $\left\{\sigma_{n}, \tau_{t}, \tau_{s}\right\}$ and is expressed by:

$$
\left(\sigma_{n} / \sigma_{\mathrm{adh}}^{\max }\right)^{2}+\left(\tau_{t} / \tau_{\mathrm{adh}}^{\max }\right)^{2}+\left(\tau_{s} / \tau_{\mathrm{adh}}^{\max }\right)^{2}=1
$$

where $\sigma_{n}$ is the normal stress to the surface of the adhesive layer, whereas $\tau_{t}$ and $\tau_{s}$ are the shear stress components along the adhesive layer.

The failure criterion in the 3-D case is formulated as a power law and depends on the fracture energies in the three considered modes: normal $n=\mathrm{I}$ and 2 tangential: $t=\mathrm{II}, s=\mathrm{III}$ :

$$
\left(G_{I} / G_{I c}\right)^{2}+\left(G_{I I} / G_{I I c}\right)^{2}+\left(G_{I I I} / G_{I I I c}\right)^{2}=1
$$

where $G_{I c}, G_{I I c}, G_{I I I c}$ are the critical values of the fracture energies for opening or shear modes. The fracture energy $G_{I c}$ for Hysol 
9514 was estimated in [46] by performing a double cantilever beam test. The fracture energy is equal to $G_{I c}=905 \mathrm{~J} / \mathrm{m}^{2}$. Due to lack of experimental data, it was assumed that $G_{I I c}=G_{I I I c}=G_{I c}$, i.e. the failure of the cohesive layer is isotropic.

\section{Numerical results}

\subsection{Purely adhesive joints}

The numerical results for the adhesive joint are presented in Figs 6 and 7. In Fig. 6a we observe reduced stress distribution at the moment of damage initiation in the adhesive layers. The stress concentration takes place in the ends of the overlap region, but the level of stress is below yield limit $\sigma_{y}^{\text {st }}=300 \mathrm{MPa}$. The external load $P$ is carrying by the whole overlap region of the sample, i.e. both adhesive layers have the initial dimension (moment of damage initiation, Fig. 7a). Due to the stress concentration at the ends of the adhesive layers, the damage initiation criterion (1) is satisfied and the degradation process begins from the adhesive edges. The central parts of the adhesive layers (70\%) are subjected to a low level of stress and do not bear a significant amount of the total load $P$.

When the deformation process becomes very advanced we observe intensive degradation of the adhesive layers (Fig. 7b). Progression of damage fronts is shown in Fig. $7 \mathrm{~b}$ and in the final stage of deformation only small region $(30 \%)$ of the lap is still able to transmit the external force $P$. The major parts of the adhesive layers area are fractured due to fulfilment of the fracture criterion (2). The value of the reduced stresses increase, but the adherends still stay elastic.

\subsection{Rivet-adhesive joints}

Figures 8 and 9 present characteristic deformation stages of the rivet-adhesive joints under tensile force $P$. The first figure shows the Huber - von Mises stress distribution in the joint corresponding to the end of the elastic response (point A in Fig. 10b). The joint has a non-symmetric structure in relation to the middle horizontal plane due to the riveting process. It is important to notice (Fig. 8) that the end of the middle adherend and ends of the outer adherends exhibit a lower level of equivalent stress in comparison to strip parts out of overlap region. Moreover, one can see the stress concentrations in the rivet region. The riveting process introduces compressive stresses in the joint and therefore the equivalent Huber - von Mises stresses are reduced in the rivet area. The state before final failure (point B, Fig. 10b) and high stress concentrations are observed in the upper external adherend due to total decohesion in both adhesive layers. Then initiation of the shear cutting rivet takes place (Fig. 9).

Figure 10 presents a comparison of experimental and numerical results. Both shapes of the force-displacement curves for the purely adhesive (Fig. 10a) and complex joints (Fig. 10b) are similar. However, the failure force (points B) in case of the purely adhesive joint was increased by the rivet component for the complex joint. At point A, the damage process initiates in the adhesive layers, whereas at point B the total load capacity a)

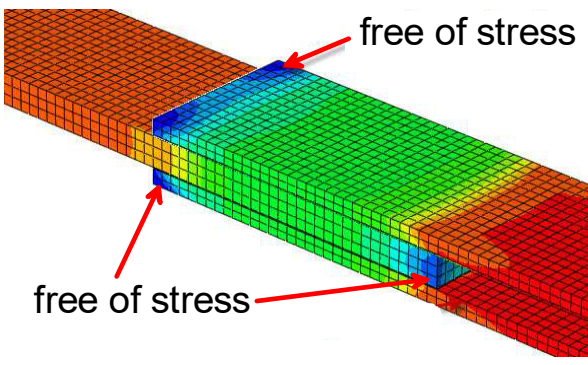

Fig. 6. Distribution of the reduced stress in purely adhesive joints: a) damage initiation, b) just before the final failure

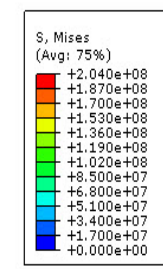

b)

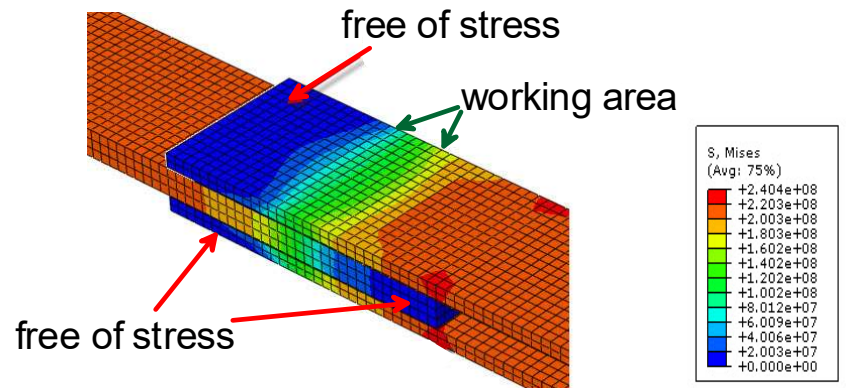

\section{damage initiation in adhesive layer}

a)

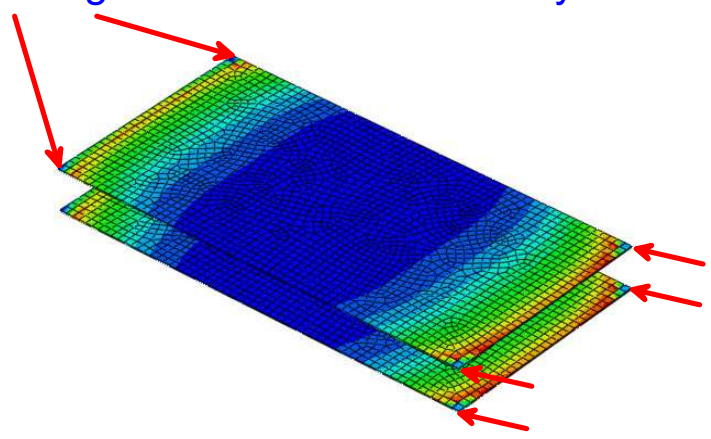

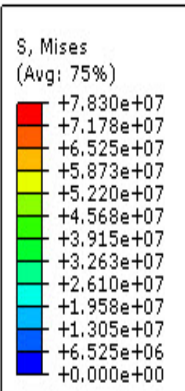

b)

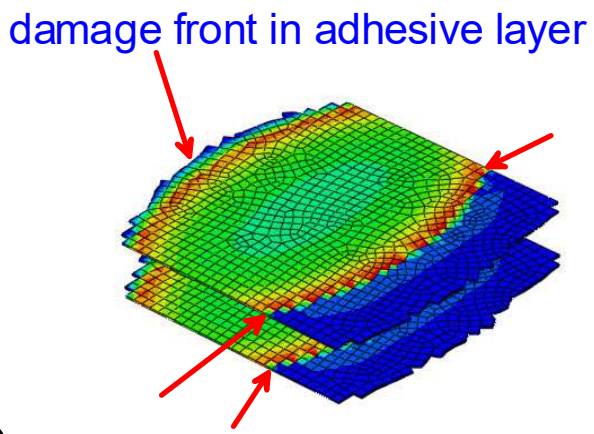

Fig. 7. Damage growth in the adhesive layer: a) damage initiation, b) damage state just before the final failure 

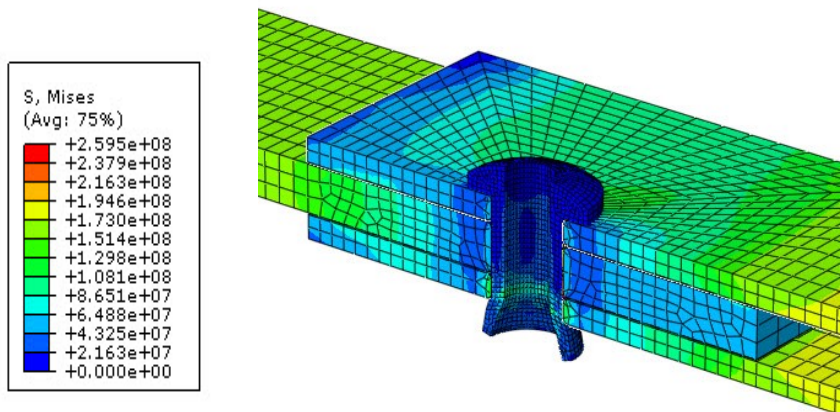

Fig. 8. Elastic response of the rivet-adhesive joint preceding initiation of damage in the adhesive (point A in Fig. 10b)

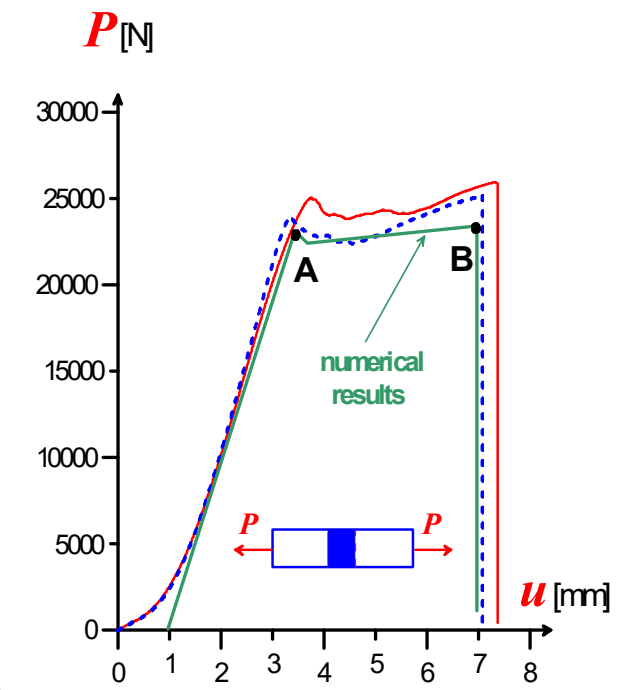

a)

b)

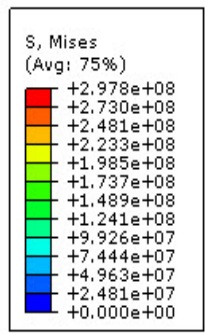

initiation of the rivet cutting process

Fig. 9. Final stage of deformation initiated by shear rivet cutting

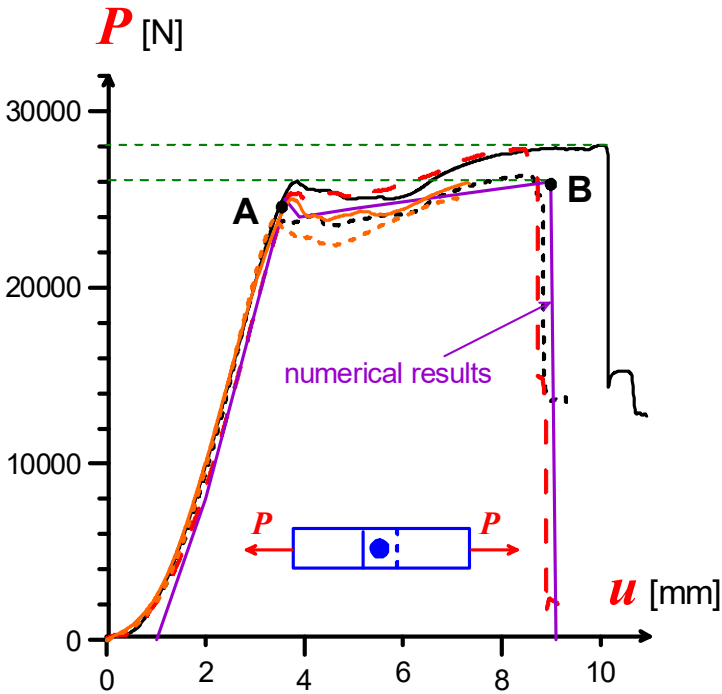

Fig. 10. Comparison of experimental and numerical results for: a) the purely adhesive joints, b) the rivet-adhesive joints of adhesive layers is reached and the shearing of the rivet starts, Fig. 10b.

It is necessary to point out that in all analysed types of joints, the level of stresses in the steel adherends does not overcome the yield stress $\sigma_{y}^{\text {st }}=300 \mathrm{MPa}$. Therefore, in the analysis we omit description of a plastic damage process in all the adherends.

Figure 10 presents also comparison between experimental and numerical results. The numerical modelling with the assumptions introduced above compare well with the experiments, although in the final stage the estimated force is lower than of the experiments. The initiation of the degradation process in the adhesive layers starts at point $\mathrm{A}$ and the final stage is at point $\mathrm{B}$.

\section{Conclusions}

The paper presents experimental and numerical investigations of the adhesively bonded and rivet-adhesive joints. The DIC system allowed for non-destructive experimental monitoring of the joint behaviour up to final failure and observations of decohesion zones in the adhesive layers. The numerical analysis, with application of a cohesive zone model was convenient for the description of the adhesive and hybrid joints. The obtained numerical results are well fitted with the experimental data. Summarizing, the following major conclusions can be formulated:

- the Hysol 9514 adhesive creates very effective adhesive bonding of the steel adherends exhibiting a very high energy absorption;

- the strengthening of double lap adhesive joints by rivets significantly improve both the static strength and the stiffness of joint;

- the two stage fracture process (first in the adhesive and the second by cutting of rivets) in the considered rivet-adhesive joints significantly increases (35\%) the energy absorption up to final failure;

- the stiffening effects by application of additional riveting of the purely adhesive connection lead to a higher reliability and durability of structural joining of different parts applied in: automotive, aerospace, civil and other branches of engineering.

Further investigations are necessary to analyse the joint behaviour with different adhesives types of loading. Moreover, different degradation and cracking models (e.g. [37-47]) should be incorporated in the analysis to get more detailed mechanical response. 


\section{Acknowledgement}

This work was financially supported by Ministry of Science and Higher Education (Poland) within the statutory research number S/20/2017.

\section{REFERENCES}

[1] V. Birman, L.V. Bryd, Modelling and Analysis of Functionally Graded Materials and Structures, Appl. Mech. Rev. 60, 195-216 (2007).

[2] L.A. Gömze, L.N. Gömze, Alumina-based hetero-modulus ceramic composites with extreme dynamic strength - phase transformation of $\mathrm{Si}_{3} \mathrm{~N}_{4}$ during high speed collision with metallic bodies, Ěpitöanyag - Journal of Silicate Based and Composite Materials 61, 38-42 (2009).

[3] L.A. Gömze, L.N. Gömze, Ceramic-based lightweight composites with extreme dynamic strength - IOP Conf. Ser., Mater. Sci. Eng. 47012033 http://dx.doi.org/10.1088/1757-899X/47/1/012033.

[4] T. Sadowski, A. Neubrand, Estimation of the crack length after thermal shock in FGM strip, Int. J. Fract. 127, 135-140 (2004).

[5] M. Birsan, H. Altenbach., T. Sadowski, V. Eremeyev, D. Pietras, Deformation analysis of functionally graded beams by the direct approach", Composites: Part B 43, 1315-1328 (2012)

[6] I. Ivanov, T. Sadowski, D. Pietras, Crack propagation In functionally graded strip", European Physical Journal Special Topics 222, 1587-1595 (2013).

[7] V. Petrova, T. Sadowski, Theoretical modeling and analysis of thermal fracture of semi-infinite functionally graded materials with edge cracks, Meccanica 49, 2603-2615 (2014).

[8] J. Gajewski, T. Sadowski, Sensitivity analysis of crack propagation in pavement bituminous layered structures using a hybrid system integrating Artificial Neural Networks and Finite Element Method, Comput. Mat. Sci. 82, 114-117 (2014).

[9] T. Sadowski, S. Hardy, E. Postek, Prediction of the mechanical response of polycrystalline ceramics containing metallic inter-granular layers under uniaxial tension, Comput. Mat. Sci. 34, 46-63 (2005).

[10] T. Sadowski, S. Hardy, E. Postek, A new model for the time-dependent behaviour of polycrystalline ceramic materials with metallic inter-granular layers under tension, Mat. Sci. Eng. A 424, 230-238 (2006).

[11] T. Sadowski, E. Postek, Ch. Denis, Stress distribution due to discontinuities in polycrystalline ceramics containing metallic inter-granular layers, Comput. Mat. Sci. 39, 230-236 (2007).

[12] H. Dębski, T. Sadowski, Modelling of microcracks initation and evolution along interfaces of the $\mathrm{WC} / \mathrm{Co}$ composite by the finite element method, Comput. Mat. Sci. 83, 403-411 (2014).

[13] J. Bieniaś, H. Dębski, B. Surowska, T. Sadowski, Analysis of microstructure damage in carbon/epoxy composites using FEM, Comput. Mat. Sci. 64, 168-172 (2012)

[14] T. Sadowski, P. Golewski, The influence of quantity and distribution of cooling channels of turbine elements on level of stresses in the protective layer TBC and the efficiency of cooling, Comp. Mater. Sci. 52, 293-297 (2012).
[15] T. Sadowski, P. Golewski, Detection and numerical analysis of the most efforted places in turbine blades under real working conditions, Comp. Mater. Sci. 64, 285-288 (2012).

[16] N.L. Savchenko, I.N. Sevostyanova, T. Sablina, L. Molnar, R. Geber, L.A. Gömze, S.N. Kulkov, L.N. Gömze, The influence of porosity on the elasticity and strength of alumina ceramics, Ëpitöanyag - Journal of Silicate Based and Composite Materials 66, 44-34 (2014).

[17] A.V. Pocius, Adhesion and adhesives technology, Hasner, New York (1997).

[18] R.D. Adams, J. Comyn, W.C. Wake, Structural adhesive joints in engineering. $2^{\text {nd }}$ ed. Chapman\&Hall, London (1997).

[19] L.F.M. da Silva, A. Öchsner (Eds), Modelling of adhesively bonded joints, Springer (2008).

[20] L.F.M. da Silva, P.J.C. das Neves, R.D. Adams, J.K. Spelt, Analytical models of adhesively bonded joints - Part I: Literature survey, Int. J. Adhes. \& Adhes. 29, 319-330, (2009).

[21] L.F.M. da Silva, P.J.C. das Neves, R.D. Adams, J.K. Spelt, Analytical models of adhesively bonded joints - Part II: Comparative study, Int. J. Adhes. \& Adhes. 29, 331-341, (2009).

[22] L.F.M. da Silva, A. Öchsner, R.D. Adams, Handbook of Adhesion Technology, Springer (2011).

[23] L.F.M. da Silva, A. Öchsner, A.Pirondi (Eds), Hybrid adhesive joints, Springer (2011).

[24] T. Sadowski, P. Golewski, E. Zarzeka-Raczkowska, Damage and failure processes of hybrid joints: adhesive bonded aluminium plates reinforced by rivets, Comp. Mater. Sci. 50, 1256-1262 (2011).

[25] S.M.H. Darwish, Science of weld-adhesive joints, in da Silva, L.F.M. Pirondi, A. Öchsner A. (Eds), Hybrid adhesive joints, (Springer, 2011) p. 1-36.

[26] T. Sadowski, P. Golewski, M. Kneć, Experimental investigation and numerical modelling of spot welding-adhesive joints response, Composite Structures 112, 66-77 (2014).

[27] T. Sadowski, M. Kneć, P. Golewski, Spot welding-adhesive joints: modeling and testing, Journal of Adhesion 90, 346-364 (2014).

[28] J. Gajewski, P. Golewski, T. Sadowski, Geometry optimization of a thin-walled element for an air structure using hybrid system integrating artificial neural network and finite element method, Comp. Struct. 159, 589-599 (2017).

[29] A. Pirondi, F. Moroni, Science of Clinch-Adhesive Joints, in Hybrid adhesive joints. Advanced Structured Materials 6, Springer 2011, L.F.M. da Silva, A. Pirondi, A. Öschner (Eds), pp. 109-147.

[30] F. Moroni, A. Pirondi, F. Kleiner, Experimental analysis and comparison of the strength of simple and hybrid structural joints, Int. J. Adh\&Adhes 30, 367-379 (2010).

[31] T. Balawender, T. Sadowski, Experimental and numerical analyses of clinched and adhesively bonded hybrid joints, J. Adhes. Sci. Technol. 25, 2391-2407 (2011).

[32] T. Sadowski, P. Golewski, Numerical study of the prestressed connectors and their distribution on the strength of a single lap, a double lap and hybrid joints subjected to uniaxial tensile test, Archives of Metallurgy and Materials 58, 581-587 (2013).

[33] A. Needleman, A continuum model for void nucleation by inclusion debonding, J. Appl. Mech. 54, 525-531, (1987). 
[34] V. Tvergaard, J. Hutchinson, The relation between crack growth resistance and fracture process parameters in elastic-plastic solids, J. Mech. Phys. Solids 40, 1377-1397 (1992).

[35] L. Marsavina, T. Sadowski, Fracture parameters at bi-material ceramic interfaces under bi-axial state of stress, Comp. Mater. Sci, 45, 693-697 (2009).

[36] L. Marsavina, T. Sadowski, Kinked cracks at a bi-material ceramic interface - numerical determination of fracture parameters, Comput. Mat. Sci. 44, 941-950 (2009).

[37] V. Burlayenko, T. Sadowski, A numerical study of the Nonlinear dynamic analysis of harmonically excited debonded sandwich plates using finite element modeling, Composite Structures 108, 354-366 (2014).

[38] V. Burlayenko, T. Sadowski, A numerical study of the dynamic response of sandwich plates initially damaged by low-velocity impact, Comput. Mat. Sci. 52, 212-216 (2009).

[39] V. Burlayenko, T. Sadowski, A numerical study of the dynamic response of sandwich plates initially damaged by low-velocity impact, Comput. Mat. Sci. 52, 212-216 (2012).

[40] L. Marsavina, T. Sadowski, Stress intensity factors for an interface kinked crack in a bi-material plate loaded normal to the interface, Int. J. Frac. 145, 237-243 (2007).
[41] T. Sadowski, L. Marsavina, Multiscale modelling of two-phase ceramic matrix composites, Comput. Mat. Sci. 50, 1336-1346 (2011).

[42] T. Sadowski, B. Pankowski, Numerical modelling of two-phase ceramic composite response under uniaxial loading, Composite Structures 143, 388-394 (2016).

[43] T. Sadowski, S. Samborski, Modelling of porous ceramics response to compressive loading, J. Am. Cer. Soc. 86, 2218-2221(2003).

[44] T. Sadowski, S. Samborski, Development of damage state in porous ceramics under compression, Comp. Mater. Sci. 43, 75-81 (2008).

[45] T. Sadowski, G. Golewski, Effect of aggregate kind and graining on modeling of plain concrete under compression, Comput. Mat. Sci. 43, 119-126 (2018).

[46] E. Postek, T. Sadowski, Assesing the influence of porosity in the deformation of metal-ceramic composites, Comp. Interfaces 18, 57-76 (2011).

[47] L. Marsavina, E. Linul, V. Tudor, T. Sadowski, A comparison between dynamic and static fracture toughness of polyurethane foams, Polymer Testing 32, 673-680 (2013). 